\title{
Análise de plantas de apartamentos em João Pessoa, PB (1980-2016): renovações e reproduções nos arranjos espaciais
}

\author{
Analysis of apartments designs in João Pessoa, PB (1980- \\ 2016): renovations and reproductions in spatial \\ arrangements
}

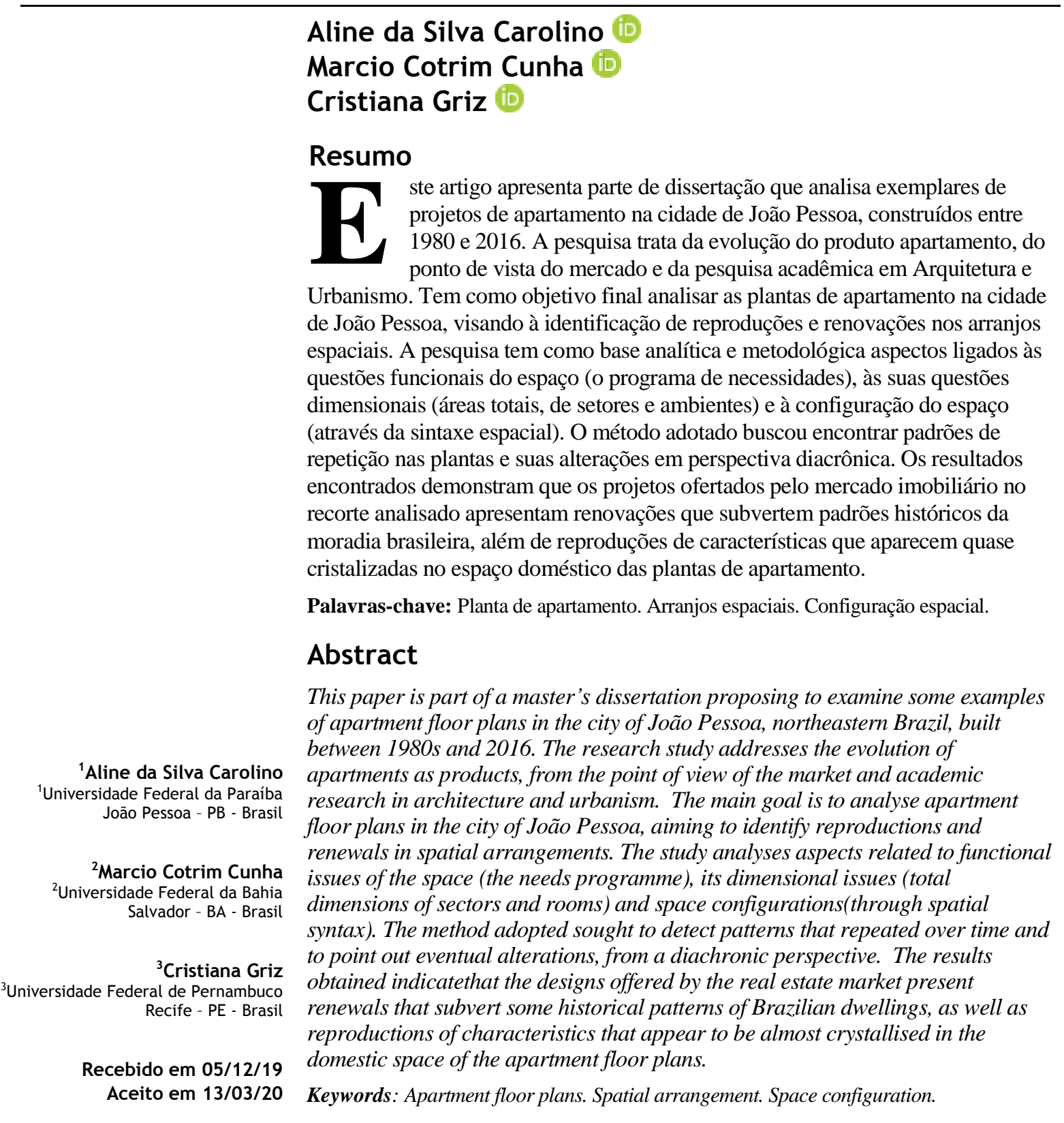

CAROLINO, A. da S.; CUNHA, M. C.; GRIZ, C. Análise de plantas de apartamentos em João Pessoa, PB (1980-2016): 


\section{Introdução}

Este artigo apresenta parte dos resultados da dissertação de mestrado que analisou plantas de apartamentos na cidade de João Pessoa, de edifícios construídos entre 1980 e 2016. O ponto de partida foi a percepção, a partir dos anos 1970, no Brasil, de importantes mudanças no perfil familiar. Muitos fatores irão transformar os grupos domésticos e, por consequência, os modos de morar e o espaço da habitação (TRAMONTANO, 1993). Na Região Nordeste, nesse período, há uma grande aceitação do modo de morar em apartamentos. Esse modelo deixa de ser associado à habitação social e passa cada vez mais a ser aceito pelas classes mais abastadas como símbolo de modernização e progresso (CHAVES, 2014).

Muitos são os estudos arqueológicos, antropológicos e sociais cujo objeto de estudo é o espaço de morar (AUGÉ, 1992; DAMATTA, 1991; KENT, 1997; TRAMONTANO, 2004). Isso ocorre tendo em vista que na planta das casas e apartamentos está contido o espaço doméstico, o lar, a residência, e esse pode ser considerado como um dos meios de se apresentar aspectos culturais e padrões sociais. Assim, o lar vai muito além de seus valores estéticos; a história social está embutida nos espaços e no modo de usá-los.

As demandas dos habitantes sobre o espaço de morar derivam de seus modos de vida, conceito oriundo das ciências sociais que relacionam o indivíduo com seus grupos comuns, definidos conforme as normas sociais por eles aceitas. Resultantes dos diversos modos de vida há variadas maneiras de se ocupar os espaços e neles exercer suas atividades. Esses comportamentos podem ser denominados de diversas formas: modos de morar, jeito de morar, modos de habitar, ou ainda maneiras de habitar (TRAMONTANO, 2007; PAULA, 2007; FRANÇA, 2008; GRIZ, 2012). E muitos são os aspectos que influenciam nos diferentes modos de ocupar o espaço doméstico.

Estudos provenientes das ciências sociais sobre o espaço de morar sugerem que uma das principais interferências sociais sobre o espaço doméstico são as mudanças nos arranjos familiares (TRAMONTANO, 2004; TRIGUEIRO, 1997; PAULA, 2007; FRANÇA, 2008). Esse espaço é, por excelência, o lócus da vida familiar, e transições no perfil das famílias supostamente deveriam acarretar mudanças espaciais, para atender aos novos arranjos. No entanto, o mercado imobiliário, influenciado por fatores econômicos e facilitadores da construção civil, continua a oferecer apartamentos que visam atender às necessidades de um único tipo, a família nuclear; esse, por sua vez, vem perdendo hegemonia com o advento dos novos arranjos familiares (SANT'ANNA, 1998; FRANÇA, 2008; VILLA, 2012).

Novos arranjos familiares demandam novos modelos na disposição dos espaços domésticos, assim como o número cada vez mais restrito de membros das famílias. Villa (2012) aponta na Região Nordeste uma queda de 7,5 para 2,0 no número de filhos por mulher entre os anos 1970 e 2009, segundo a Pesquisa Nacional por Amostra de Domicílio (PNAD) do Instituto Brasileiro de Geografia e Estatística (IBGE); e uma quantidade de 3,4 pessoas por famílias nesse último ano. O aumento da expectativa de vida resulta, entre outras coisas, no aumento da população idosa, a qual passa a fazer parte da família nuclear ou constituir novos modelos familiares, com pessoas idosas morando sós. Há ainda os casais sem filhos, chegando até aos arranjos familiares unipessoais, ou seja, pessoas morando sós (TRAMONTANO, 1997).

Há muitas influências para formação de novos arranjos familiares, dentre eles os acontecimentos históricos que interferem na posição da mulher perante a sociedade, desde a alfabetização a partir do século XX e o direito ao voto em 1934. Nas décadas de 1960 e 1970, com o advento da pílula anticoncepcional e a legalização do divórcio, a mulher passa a ter mais autonomia sobre a procriação e, frente à necessidade econômica, busca e ganha mais espaço no mercado de trabalho.

Ainda dentro do contexto feminino no espaço de morar, parece salutar observar o papel da funcionária doméstica ao longo desse período de transformação social. Diante dessa série de conquistas legais, estão também as mulheres que se "encarregam" de parte das funções domésticas da casa, as empregadas domésticas. Essa categoria atualmente se difere em dois grupos, aquelas que são residentes ou não no local de trabalho e recebem salário mensal, as mensalistas, e aquelas que não residem e recebem pagamento diário, as diaristas (MELO, 1998).

Embora esses dados ainda não sejam totalmente verificados no Nordeste do Brasil, entre os anos de 1970 e 1980 o número de mulheres que trabalham como funcionárias domésticas caiu de $27 \%$ para 19,9\%, chegando a $15 \%$ em 2011. Isso se deve, além de fatores econômicos, às novas oportunidades de emprego para mulheres jovens de classes sociais mais humildes (MOTTA, 1992; FARIA; COUTINHO; MACEDO, 2013). Em contraposição, há o aumento de diaristas que já ocupam $30 \%$ do total de trabalhadoras domésticas no país, conforme indicam Faria, Coutinho e Macedo (2013, p. 5), “[...] uma das explicações é de que os ganhos são maiores, mas, há que se advertir para a perda da proteção social [...]”.

32 Carolino, A. da S.; Cunha, M. C.; Griz, C. 
Esse conjunto de conquistas das mulheres perante a sociedade ocorre em igual passo com a modificação também na legislação brasileira que passa a ter nova definição para o conceito de família. Conforme aponta Goldani (1993, p. 72), “[...] a Constituição de 1988 considera que, para efeitos de proteção do Estado, família é a união estável entre homem e mulher ou qualquer dos pais e seus descendentes [...]”, ou seja, homem e mulher assumem igualdade perante a família e os filhos no casamento e após esse, caso haja divórcio.

Dando passos mais largos, os programas governamentais que envolvem a família, bem como o IBGE, consideram como família o conjunto de pessoas que compartilham uma unidade habitacional, desvinculando o caráter de parentesco. Para Petrini, Alcantara e Moreira (2009, p. 8), a família nunca foi considerada de maneira tão relativizada na qual “[...] esta situação paradoxal segundo a qual ora a família é tudo, ora é nada, documenta o profundo processo de mudança que envolve a sociedade e revela a pluralidade de posturas, a diversidade de valores e metas que se encontram em nossa cultura [...]". Segundo Villa (2012), esse processo de transformação dos arranjos familiares é irreversível e com forte influência cultural alterando valores, crenças, sentimentos, atingindo todos os segmentos sociais.

No entanto, parecem ser muito sutis as repercussões desses novos arranjos familiares e novos costumes no espaço doméstico. Para Tramontano (1997, p. 5), a manutenção no padrão de divisão dos projetos de apartamento "[...] permanece intocado, sob a alegação de que se chegou a resultados projetuais economicamente viáveis, que atendem às principais necessidades de seus moradores [...]". Sant'anna (1998) confirma que se mantém uma tripartição espacial (nos setores social, íntimo e serviço) sem ao menos considerar que também a família nuclear, ao qual ela se destina, se modificou.

Tais afirmações e alguns dos argumentos presentes no trabalho de diversos autores serviram como motivadores dessa pesquisa. Amorim e Loureiro (2005), por exemplo, apontam para o fato de que as "[...] mudanças na estrutura de valores acarretam mudanças no projeto, assim como no uso dos espaços e nos símbolos [...]". Estudos correlatos afirmam haver uma manutenção no padrão moderno de habitação (FRANÇA, 2008) e a adequação aos novos costumes por meio de reformas em apartamentos de alto padrão (GRIZ, 2012).

Um conjunto de premissas, das mais diversas naturezas investigativas, define a questão central da pesquisa: em que medida os projetos dos edifícios de apartamento em João Pessoa mantiveram ou modificaram suas características no decorrer do tempo, segundo o programa de necessidades habitacional, os aspectos dimensionais e configuracionais da planta? Como forma de ensaiar uma possível resposta, o objetivo deste trabalho foi analisar as plantas de apartamento na cidade de João Pessoa; centrada na comparação entre as plantas-tipo dos edifícios de apartamento localizados nos bairros adjacentes ao eixo da Avenida Epitácio Pessoa, uma das mais importantes da cidade, no período entre 1980 e 2016, visando à identificação de reproduções e renovações nos arranjos espaciais.

Este estudo se desenvolve de maneira a complementar outros trabalhos que analisam o processo de verticalização da cidade. Não foram considerados aspectos volumétricos, nem mesmo os impactos na paisagem urbana ou temas afins. Para análise dos projetos de apartamento deter-se-á apenas às plantas baixas, suas eventuais transformações durante os anos e seus possíveis motivos sociais.

\section{Método e objeto empírico}

O presente estudo caracteriza-se como uma pesquisa documental, mediante levantamento e estudo das plantas dos apartamentos, bem como uma pesquisa exploratória, com o aprofundamento e explicitação do problema estudado por meio de estudos de caso.

Foi selecionada para análise a faixa norte da Avenida Epitácio Pessoa, um importante eixo estruturador urbano e histórico para a cidade de João Pessoa. A pesquisa abordou os bairros Tambaú, Miramar, Jardim Luna e Bairro dos Estados - bairros que margeiam a faixa norte da avenida supracitada - desde a década de 1980 ao ano de 2016. Realizou-se o levantamento in loco das edificações em altura, construídas no recorte espacial delimitado, computando um total de 264 edifícios de habitação multifamiliar com no mínimo três andares.

Elaborou-se um mapa, situando os edifícios (Figura 1), e uma planilha (Tabela 1), na qual foram colocados os dados coletados no levantamento (nome do edifício, logradouro e número de pavimentos) e acrescentadas as seguintes informações:

(a) ano do projeto; 
(b) ano da construção (habite-se);

(c) quantidade de plantas-tipo;

(d) construtora; e

(e) $\operatorname{arquiteto(a)}$

Essas informações foram coletadas junto a outras pesquisas (DINIZ, 2013), aos escritórios de arquitetura, às construtoras e à Prefeitura Municipal de João Pessoa (PMJP). Além disso, foi feita a coleta das plantas baixas nas mesmas fontes supracitadas; obteve-se um total de 174 edifícios com todas ou parte dessas informações e teve-se acesso a 56 plantas baixas.

Foram considerados os seguintes critérios para delimitação do objeto empírico do estudo:

(a) edificações construídas no recorte espacial escolhido para análise; e

(b) edifícios que apresentem no mínimo o programa: cozinha, sala, banheiro e variações entre 1 a 4 dormitórios, pelos quais se procura trazer a diversidade da amostra com a variação de dormitórios (FRANÇA, 2008)

Determinou-se, então, um total de $48^{1}$ edifícios para análise, e, por proporção, distribuiu-se esse total ao longo dos bairros e décadas e, levando em consideração a variação de plantas-tipo em cada edifício, a análise foi realizada em um total de 104 plantas. Esse material foi todo redesenhado para que se obtivesse uma padronização de representação e catalogado em fichas que compõem o apêndice da dissertação ao qual este artigo se refere.

As plantas dos apartamentos selecionadas foram analisadas por meio da associação entre as metodologias adotadas por Griz (2012) e França (2008). O resultado é um conjunto de ferramentas a partir das quais se observaram três dimensões: função, forma e organização espacial, divididas em três variáveis analíticas:

(a) o programa de necessidades, cujo objetivo é identificar o uso proposto para cada espaço dos apartamentos;

(b) a dimensão geométrica do espaço, reconhecendo os diferentes setores, suas áreas e a distribuição dessas entre os rótulos principais;

(c) a configuração espacial, por meio da análise sintática da planta, observando as propriedades relacionais entre os espaços.

Ao ser feita uma primeira análise global sobre a amostra percebeu-se a similaridade de resultados para plantas com número de quartos e área total próximas, tendo sido esse o parâmetro de comparação adotado nesta pesquisa.

\section{Análise funcional}

Para este artigo, foram consideradas as prescrições aos quais os ambientes se destinam, identificando os possíveis usos que lhes foram atribuídos. Os termos adotados tiveram como referência as plantas apresentadas. Entende-se por uso aquele que estiver previsto na planta e não são consideradas as variações das atividades que possam vir a ocorrer após a ocupação do apartamento.O objetivo dessa etapa foi identificar os ambientes que permaneceram, os que foram alterados, suprimidos ou inseridos nas plantas com o decorrer do tempo.

A sistematização dos dados foi feita por meio de tabelas, por período em que a cada rótulo é atribuída a pontuação 1 cada vez que aparece nas plantas (Tabela 2), conforme adotado por Griz (2012). Para atingir o objetivo desta etapa, o método adotado permitiu, por meio da visualização da tabela, observar os rótulos que se mantiveram em todos os edifícios, mostrando a importância dada a certos ambientes que se repetem em uma época, mas não fazem parte do programa mínimo da habitação. Dividir a tabela em setores também permitiu ver como se deu a alteração não apenas nos rótulos individualmente.

\footnotetext{
${ }^{1}$ Para delimitação do número de edifícios a serem analisados, após consultas ao laboratório de estatística da UFPB, tomou-se como base o método estatístico de conveniência para delimitar o total de plantas, isso devido ao fato de a amostra ser pequena do ponto de vista da estatística. Determinou-se, então, um total de 50 edifícios para análise, e ao arredondar os valores percentuais distribuídos para os bairros, chegou-se a um total de 48 edifícios.
}

34 Carolino, A. da S.; Cunha, M. C.; Griz, C. 
Figura 1 - Mapa de ocupação vertical do recorte estudado em março de 2017

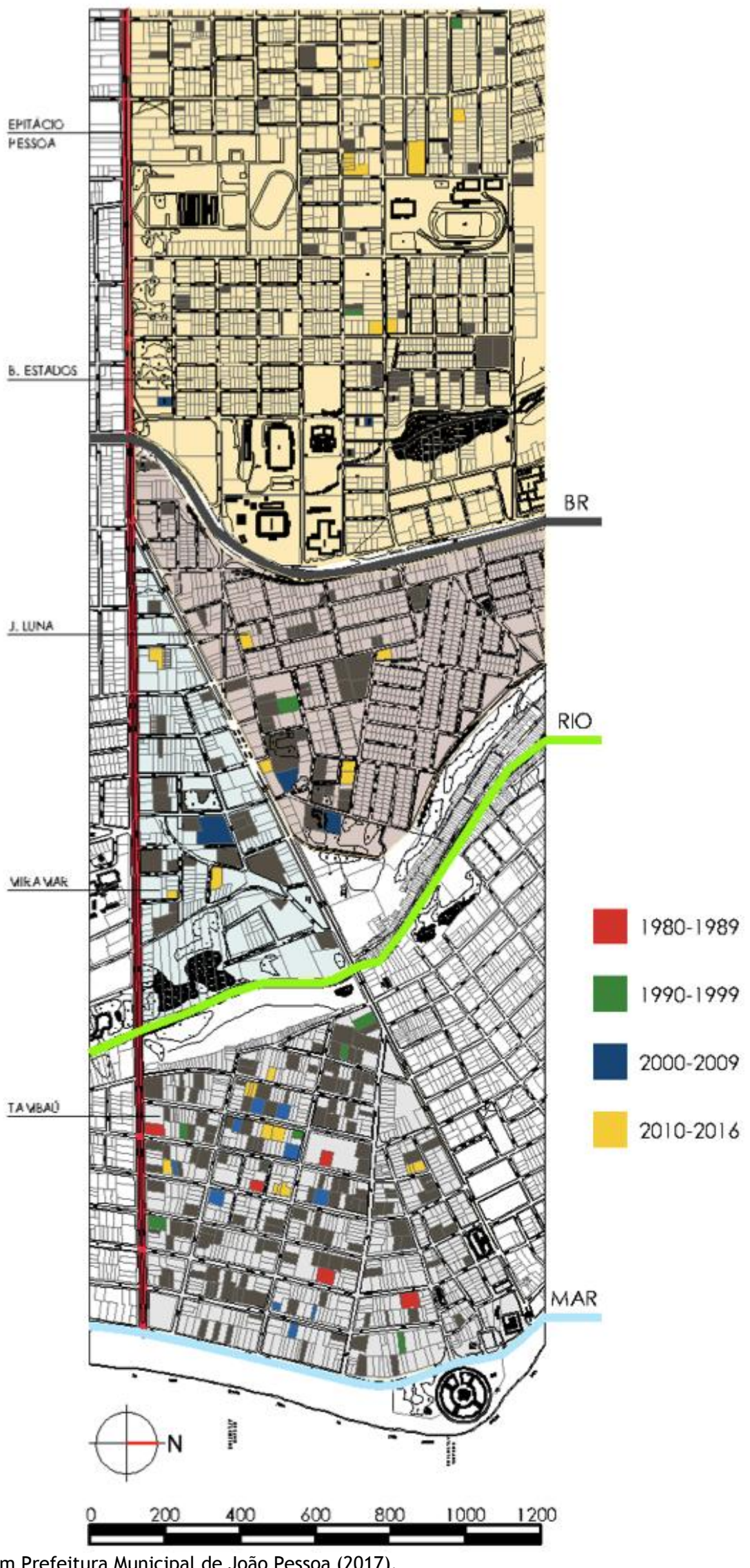

Fonte: baseado em Prefeitura Municipal de João Pessoa (2017). 
Tabela 1 - Informações dos edifícios escolhidos para análise (Continua...)

\begin{tabular}{|c|c|c|c|c|c|c|c|}
\hline Nome do edifício & $\begin{array}{l}\text { Ano } \\
\text { Proj }\end{array}$ & $\begin{array}{c}\text { Ano } \\
\text { Habite- } \\
\text { se }\end{array}$ & $\begin{array}{l}\mathrm{N}^{\circ} \text { de } \\
\text { pav. }\end{array}$ & $\begin{array}{c}\mathrm{N}^{\circ} \text { de } \\
\text { apto por } \\
\text { andar }\end{array}$ & $\begin{array}{c}\mathbf{N}^{\circ} \text { de } \\
\text { quartos }\end{array}$ & Construtora & Arquiteto \\
\hline \multicolumn{8}{|l|}{$\overline{\text { TAMBAÚ }}$} \\
\hline \multicolumn{8}{|l|}{$1979-1989$} \\
\hline 1.Solar dos Navegantes & - & 1979 & 12 & 4 & $3-4$ & Holanda & \\
\hline 2.Clarissa VI & - & 1986 & 10 & 4 & 3 & Tadeu Pinto & \\
\hline 3.Jamaica & - & 1986 & 12 & 2 & 3 & Enarq & \\
\hline 4.Solar da Praia & - & 1988 & 12 & 4 & $3-4$ & Holanda & \\
\hline 5.Tropicus & - & 1988 & 12 & 2 & 3 & Conscivel & \\
\hline \multicolumn{8}{|l|}{ 1990-1999 } \\
\hline 1.Edf. Angelus & 1996 & 1998 & 4 & 4 & 3 & & $\begin{array}{l}\text { Lizia Paiva } \\
\text { e Germana } \\
\text { Rocha }\end{array}$ \\
\hline 2.Edf. José Lucas & 1996 & 1999 & 8 & 2 & 4 & Proenco & $\begin{array}{l}\text { Valéria } \\
\text { Simões }\end{array}$ \\
\hline 3.Filadelfia & 1996 & 1999 & 13 & 2 & 3 & W3 & $\begin{array}{l}\text { Jussara } \\
\text { Chianca e } \\
\text { Débora } \\
\text { Pires } \\
\end{array}$ \\
\hline 4.Maison de France & 1995 & 1999 & 8 & 4 & 4 & Cobrás & $\begin{array}{l}\text { Lizia Paiva } \\
\text { e Andrea } \\
\text { Cruz }\end{array}$ \\
\hline 5.Poliedro III & 1992 & 1999 & 9 & 4 & 3 & Poliedro & \\
\hline 6.Res. Cap. Taigy & - & 1998 & 3 & 3 & 3 & Taigy & \\
\hline \multicolumn{8}{|l|}{$2000-2009$} \\
\hline 1. Res. Ana Emília & 1996 & 2001 & 15 & 2 & $3-4$ & $\begin{array}{l}\text { NB } \\
\text { Engenharia }\end{array}$ & $\begin{array}{l}\text { Fábio } \\
\text { Queiroz }\end{array}$ \\
\hline 2.Milton Cavalcanti & 2002 & 2004 & 6 & 2 & 3 & $\begin{array}{l}\text { EC } \\
\text { Construções }\end{array}$ & $\begin{array}{l}\text { Paulo } \\
\text { Macedo }\end{array}$ \\
\hline 3.Maison Saint Marie & 2002 & 2006 & 18 & 4 & 3 & Brascon & Fábio Galisa \\
\hline 4.Boulevard Tambaú & 2003 & 2006 & 11 & 2 & 4 & $\mathrm{ABC}$ & Fábio Galisa \\
\hline 5.Residencial José Olinto & 2004 & 2009 & 5 & 5 & 2 & $\begin{array}{l}\text { EC } \\
\text { Construções }\end{array}$ & $\begin{array}{l}\text { Paulo } \\
\text { Macedo }\end{array}$ \\
\hline $\begin{array}{l}\text { 6.Tambaú Palace } \\
\text { Residence }\end{array}$ & 2002 & 2008 & 12 & 8 & $1-2$ & Planc & $\begin{array}{l}\text { Paulo } \\
\text { Macedo }\end{array}$ \\
\hline 7.Maison Saint Martin & 2004 & 2008 & 17 & 4 & 3 & Brascon & Fábio Galisa \\
\hline 8. Park Royal & 2007 & 2009 & 6 & 6 & 2 & $\mathrm{ABC}$ & $\begin{array}{l}\text { Marcelo } \\
\text { Maia }\end{array}$ \\
\hline $\begin{array}{l}\text { 9. Atlantis Tambaú } \\
\text { Residence }\end{array}$ & 2004 & 2009 & 13 & 4 & $1-2-3$ & Atlantis & $\begin{array}{l}\text { Gilberto } \\
\text { Guedes }\end{array}$ \\
\hline 10.Lumiére Maison & 2005 & 2007 & 12 & 3 & $2-3$ & Atlanta & Fábio Galisa \\
\hline \multicolumn{8}{|l|}{$2010-2016$} \\
\hline $\begin{array}{l}\text { 1.Atlantis Plaza } \\
\text { Residence }\end{array}$ & 2009 & 2012 & 11 & 6 & $2-3$ & Atlantis & $\begin{array}{l}\text { Gilberto } \\
\text { Guedes }\end{array}$ \\
\hline $\begin{array}{l}\text { 2.Residencial Praia de } \\
\text { Tambáu }\end{array}$ & 2007 & 2014 & 16 & 3 & 3 & & $\begin{array}{l}\text { Marcelo } \\
\text { Maia }\end{array}$ \\
\hline 3.Palácio Real Tambaú & - & 2016 & 25 & $1-2$ & $3-4$ & Equilíbrio & - \\
\hline 4.Brisas de Tambaú & 2013 & 2016 & 11 & 4 & 2 & FCK & $\begin{array}{l}\text { Venâncio } \\
\text { Toscano }\end{array}$ \\
\hline 5.Maison Saint Thomas & 2012 & 2016 & 21 & $2-4$ & $2-3-4$ & Brascon & Fábio Galisa \\
\hline $\begin{array}{l}\text { 6.Atlantis Praia Bela } \\
\text { Residence }\end{array}$ & 2010 & 2013 & 11 & 2 & 3 & Atlantis & $\begin{array}{l}\text { Gilberto } \\
\text { Guedes }\end{array}$ \\
\hline
\end{tabular}

36 Carolino, A. da S.; Cunha, M. C.; Griz, C. 
Tabela 1 - Informações dos edifícios escolhidos para análise (continuação)

\begin{tabular}{|c|c|c|c|c|c|c|c|}
\hline Nome do edifício & $\begin{array}{l}\text { Ano } \\
\text { Proj }\end{array}$ & $\begin{array}{c}\text { Ano } \\
\text { Habite- } \\
\text { se }\end{array}$ & $\begin{array}{l}\mathrm{N}^{\circ} \mathrm{de} \\
\text { pav. }\end{array}$ & $\begin{array}{c}\mathrm{N}^{\circ} \text { de } \\
\text { apto por } \\
\text { andar }\end{array}$ & $\begin{array}{c}\mathbf{N}^{\circ} \text { de } \\
\text { quartos }\end{array}$ & Construtora & Arquiteto \\
\hline \multicolumn{8}{|l|}{ MIRAMAR } \\
\hline \multicolumn{8}{|l|}{$2000-2009$} \\
\hline 1. Torre Imperial & - & 2004 & 29 & 2 & 4 & & $\begin{array}{l}\mathrm{AE} \\
\text { Arquitetura }\end{array}$ \\
\hline \multicolumn{8}{|l|}{$2010-2016$} \\
\hline $\begin{array}{l}\text { 1. Residencial Maria Elisa } \\
\text { Falcone }\end{array}$ & 2010 & 2014 & 12 & 5 & $2-3$ & FCK & $\begin{array}{l}\text { Venâncio } \\
\text { Toscano }\end{array}$ \\
\hline 2. Buena Vista Residence & - & 2016 & 31 & 4 & 3 & $\begin{array}{l}\text { JE } \\
\text { Construções }\end{array}$ & \\
\hline $\begin{array}{l}\text { 3. Residencial Porto } \\
\text { Azzurro }\end{array}$ & 2008 & - & 17 & 2 & 4 & & $\begin{array}{l}\text { Marcelo } \\
\text { Maia }\end{array}$ \\
\hline \multicolumn{8}{|l|}{ JARDIM LUNA } \\
\hline \multicolumn{8}{|l|}{ 1990-1999 } \\
\hline 1. Portinari Residencial & 1998 & - & 17 & 2 & 4 & & \\
\hline \multicolumn{8}{|l|}{$2000-2009$} \\
\hline 1. Villaggio di Luna & 2006 & - & 26 & 2 & 4 & Vertical & $\begin{array}{l}\text { Paulo } \\
\text { Macedo }\end{array}$ \\
\hline 2. Jardim Imperial & 1997 & 2001 & 25 & 2 & 4 & & $\begin{array}{l}\text { Germana } \\
\text { Rocha }\end{array}$ \\
\hline \multicolumn{8}{|l|}{$2010-2016$} \\
\hline 1. Maison de Lyon & 2010 & - & 20 & 2 & 3 & Brascon & Fábio Galisa \\
\hline 2. Royal Luna Residence & 2011 & 2016 & 30 & 2 & 4 & Dimensional & Fábio Galisa \\
\hline 3. Holanda's Garden Place & 2009 & 2012 & 29 & 2 & $3-4$ & Holanda & $\begin{array}{l}\text { Venâncio } \\
\text { Toscano }\end{array}$ \\
\hline 4. Spazio di Ravenna & 2011 & - & 30 & $1-2$ & 3 & Massai & $\begin{array}{l}\text { Fábio } \\
\text { Romero }\end{array}$ \\
\hline \multicolumn{8}{|l|}{ BAIRRO DOS ESTADOS } \\
\hline \multicolumn{8}{|l|}{ 1990-1999 } \\
\hline 1. Res. Veneza & 1998 & 1999 & 5 & 4 & 3 & Alconil & $\begin{array}{l}\text { Delba } \\
\text { Borges }\end{array}$ \\
\hline 2. Res. Mar del Plata & 1997 & 1999 & 3 & 4 & 2 & & $\begin{array}{l}\text { George } \\
\text { Cruz e } \\
\text { Liliane } \\
\text { Vieria }\end{array}$ \\
\hline \multicolumn{8}{|l|}{ 2000-2009 } \\
\hline 1. Res. Pedra da Gávea & 2002 & 2006 & 10 & 4 & $2-3$ & Luza & $\begin{array}{l}\text { Germana } \\
\text { Rocha }\end{array}$ \\
\hline 2. Res. Vale Coimbra & 2008 & 2009 & 3 & 5 & $1-2$ & Áquila & $\begin{array}{l}\text { Katherine } \\
\text { Celani }\end{array}$ \\
\hline \multicolumn{8}{|l|}{ 2010-2016 } \\
\hline $\begin{array}{l}\text { 1. Residencial } \\
\text { Castelfidardo }\end{array}$ & 2010 & - & 26 & 2 & 3 & Ibérica & Fábio Galisa \\
\hline 2. Spazio de Veneza & 2015 & - & 21 & 3 & $2-3$ & Massai & $\begin{array}{l}\text { Fábio } \\
\text { Romero }\end{array}$ \\
\hline 3. Vivant Club Residence & - & 2014 & 22 & $2-4$ & $3-4$ & Alliance & $\begin{array}{l}\text { Brilhante } \\
\text { Filho }\end{array}$ \\
\hline 4. Evidence Class Club & 2011 & - & 26 & $2-3$ & $2-3$ & Alliance & $\begin{array}{l}\text { Paulo } \\
\text { Macedo e } \\
\text { Fábio } \\
\text { Queiroz }\end{array}$ \\
\hline $\begin{array}{l}\text { 5. Porto Dakar } \\
\text { Residencial }\end{array}$ & 2010 & 2016 & 20 & 3 & 3 & Unidade & $\begin{array}{l}\text { Venâncio } \\
\text { Toscano }\end{array}$ \\
\hline 6. Palácio Imperial & 2011 & 2014 & 17 & 4 & $2-3$ & Equilíbrio & $\begin{array}{l}\text { Lacerda, } \\
\text { Castro e } \\
\text { Silva }\end{array}$ \\
\hline
\end{tabular}


Tabela 2 - Modelo de tabela de sistematização dos programas de necessidades

\begin{tabular}{c|c|c|c|c|c|c|c|c|c|c}
\hline \multicolumn{1}{c|}{ Setor } & \multicolumn{3}{c|}{ Serviço } & \multicolumn{5}{c|}{ Social } & \multicolumn{5}{c}{ Íntimo } \\
\hline \multicolumn{1}{c|}{ Rótulo } & Cozinha & Serviço & DCE & Estar & Jantar & Varanda & Suíte & Quarto & WC & Varanda \\
\hline $\begin{array}{l}\text { Variação } \\
\text { do rótulo }\end{array}$ & & & & Living & & $\begin{array}{c}\text { Varanda } \\
\text { gourmet }\end{array}$ & & $\begin{array}{c}\text { Dormitório/ } \\
\text { Escritório }\end{array}$ & \\
\hline Exemplar 1 & 1 & 1 & 1 & 1 & 1 & 1 & 1 & 2 & 2 & 1 \\
\hline Exemplar 2 & 1 & 1 & 1 & 1 & 1 & 1 & 1 & 2 & 2 & \\
\hline Exemplar 3 & 1 & 1 & & 1 & 1 & 1 & 1 & 1 & 2 & \\
\hline Exemplar 4 & 1 & 1 & & 1 & 1 & 1 & 1 & 2 & 2 & \\
\hline
\end{tabular}

\section{Análise dimensional}

Para análise das dimensões das plantas, foram adotadas como critério as categorias utilizadas por França (2008):

(a) área total dos apartamentos;

(b) área dos setores (social, íntimo e serviço), considerando a proporção da área do setor para a área total do apartamento, o que permite comparar projetos com diferentes áreas e programas; e

(c) tamanho dimensional dos espaços importantes de cada setor.

Para este último foram consideradas: a cozinha para o setor de serviço, as salas de estar e jantar para o social e a suíte principal para o íntimo - onde foram computados os valores absolutos e percentuais (em relação à área total da unidade). Em todas essas categorias são considerados o período e a localidade dos apartamentos.

O objetivo de observar a área de alguns espaços isolados permite identificar as modificações que vêm sofrendo as dimensões de ambientes importantes em um apartamento, a exemplo da cozinha e suíte. Além disso, possibilita entender o quanto esses ambientes diminuem ou aumentam em relação à área do apartamento, em diferentes programas de necessidades. Os resultados foram catalogados em tabelas e gráficos.

Por meio da média aritmética de cada setor pela média aritmética da área total foi possível a análise de como se distribuíram os setores pela área do apartamento para cada década. A comparação entre as décadas permite visualizar como se comporta essa distribuição de área ao passar dos anos.

\section{Análise configuracional}

A variável configuracional descreve as propriedades topológicas e tem foco na configuração espacial da planta. Para Hanson (1998), a configuração espacial existe quando há algum tipo de conexão entre dois espaços, e a relação entre esses dois espaços muda conforme o relacionamos a um terceiro ou a qualquer número de espaços. A análise é feita por meio de propriedades relacionais, através de medidas indiretas, fundamentadas em procedimentos introduzidos pela sintaxe espacial (HILLIER; HANSON, 1984) e pode ser resumidamente descrita em três etapas: identificação e escolha da decomposição espacial em elementos espaciais; estudo da relação entre os espaços; e identificação da maneira pela qual um sistema de espaços é relacionado para formar um padrão.

Uma das formas de análise da sintaxe espacial, comumente adotada nos estudos de espaço doméstico, considera os espaços contidos na planta baixa como espaços convexos. Para interpretação desses espaços, segue-se a definição matemática do termo, em que um espaço vetorial é convexo quando todo segmento de reta que interliga dois de seus pontos está todo contido nesse espaço, que, transportando para o espaço arquitetônico, refere-se aos locais que permitem copresença, encontro e agrupamento (Figura 2).

O princípio para decomposição da planta baixa em espaços convexos é a limitação das barreiras (representadas pelas alvenarias) assimiladas aos usos do espaço descrito nas plantas ou pelo leiaute que configura os convexos funcionais (MONTEIRO, 1997).

Quanto às relações topológicas serão considerados os grafos justificados que demonstram as relações de conexão entre os espaços. São obtidos a partir da escolha de um ambiente padrão para todas as plantas, tido como raiz do grafo. Conectam-se a um primeiro nível os ambientes que se ligam à raiz, em um segundo

38 Carolino, A. da S.; Cunha, M. C.; Griz, C. 
nível conectam-se aqueles que estão ligados aos ambientes do primeiro nível e assim por diante (HILLIER; HANSON, 1984).

Para este estudo, considerou-se como raiz do grafo o espaço imediatamente externo ao apartamento, no caso os halls de elevadores e escadas. Tal escolha se dá devido ao fato de eles serem um elemento comum entre todos os sistemas e permitir, assim, uma comparação da lógica interna de cada um. Tendo esse ponto de partida, foram conectados a um primeiro nível os ambientes que se ligavam diretamente à porta de acesso dos apartamentos (salas de estar ou jantar, cozinhas, áreas de serviço e/ou halls de acesso); em um segundo nível conectaram-se aqueles que estão ligados aos ambientes do primeiro nível e assim por diante (Figura 3).

O mesmo procedimento foi feito em seguida para as relações de visibilidade, considerando o acesso visual entre os ambientes do apartamento, gerando grafos de visibilidade. A relação de acessibilidade dos espaços também pode ser observada a partir da relação entre os setores, onde se pode reduzir cada setor a um nó e interligá-los conforme a presença de conexão entre eles, gerando grafos setoriais (AMORIM, 1997). A comparação entre os resultados encontrados nos grafos justificados e mapas convexos permite identificar as mudanças ocorridas entre os períodos estudados no tocante à configuração espacial que sugere características sobre o espaço arquitetônico.

Alguns meios de observação das relações entre os espaços auxiliam no entendimento de sua configuração espacial, são eles:

(a) profundidade (medida a partir da quantidade de passos topológicos que são necessários para atingir um ponto a outro do sistema);

(b) integração por acessibilidade e visibilidade (medida que demonstra a distância topológica de um determinado espaço para todos os outros do sistema); e

(c) privacidade (identifica os níveis de privacidade e controle dos rótulos selecionados considerando sua integração por acessibilidade e visibilidade por meio do diagrama de quatro regiões - Figuras 4 e 5).

A identificação de padrões espaciais pode ocorrer por meio das inequações, cujos valores encontrados para integração de cada ambiente do sistema são expostos em ordem crescente. Nos estudos de residências (FRANÇA, 2008; GRIZ, 2012; TRIGUEIRO, 1997) são considerados os seguintes ambientes:

(a) sala;

(b) cozinha;

(c) quarto principal; e

(d) exterior.

Como nesta pesquisa o interesse é comparar como se comportam os espaços internos de diferentes apartamentos, não foi considerado o exterior. Foi utilizada neste estudo a primeira letra de cada cômodo: E:estar; J:jantar; S:suíte; e C:cozinha. Essa mesma relação pode ser dada para os setores nos quais se considera: soc:social; serv:serviço; e int:íntimo.

Figura 2 - Modelo de planta original e mapa convexo

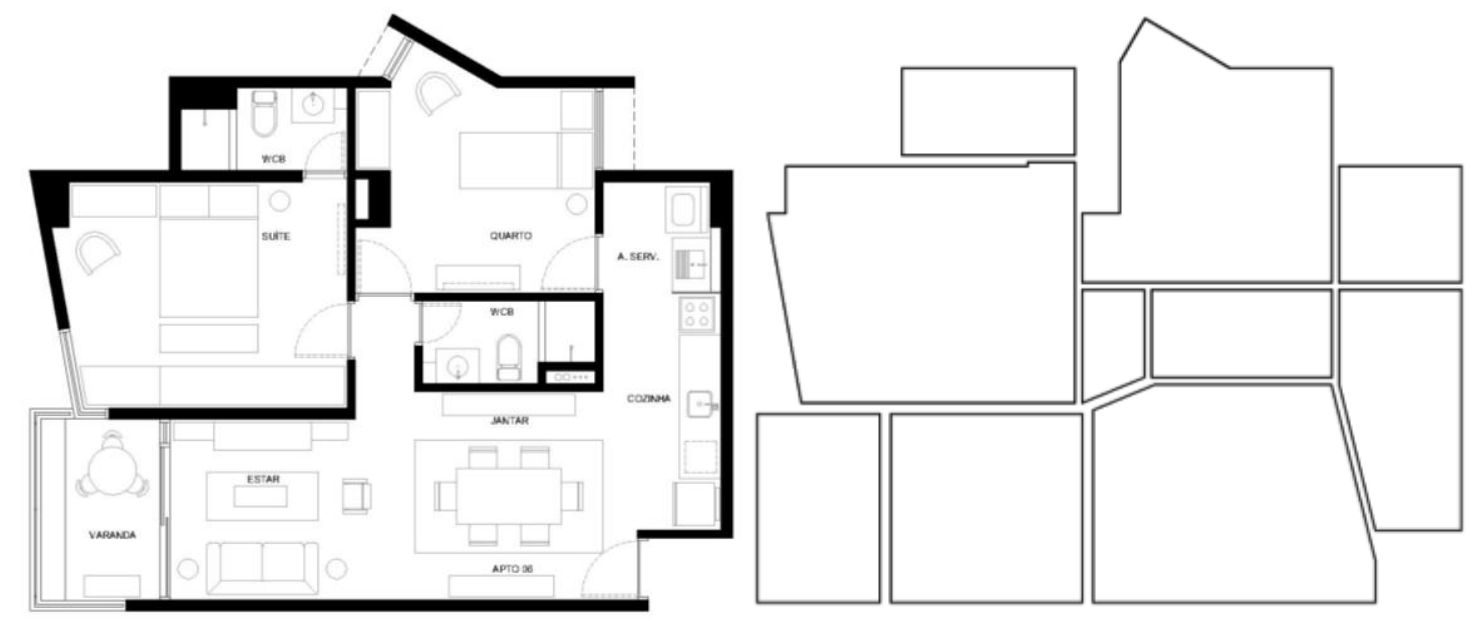

Fonte: adaptado do acervo da construtora Atlantis. 
Figura 3 - Modelo de grafo planar e grafo justificado de acessibilidade

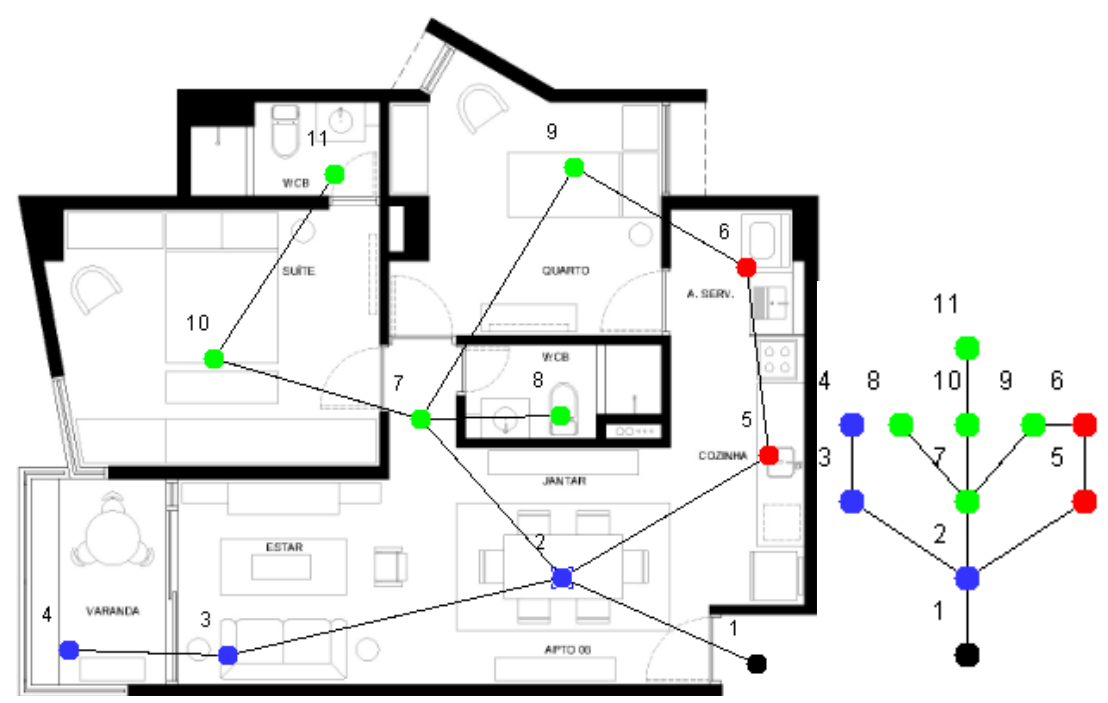

Fonte: adaptado do acervo da construtora Atlantis.

Figura 4 - Diagrama de quatro regiões

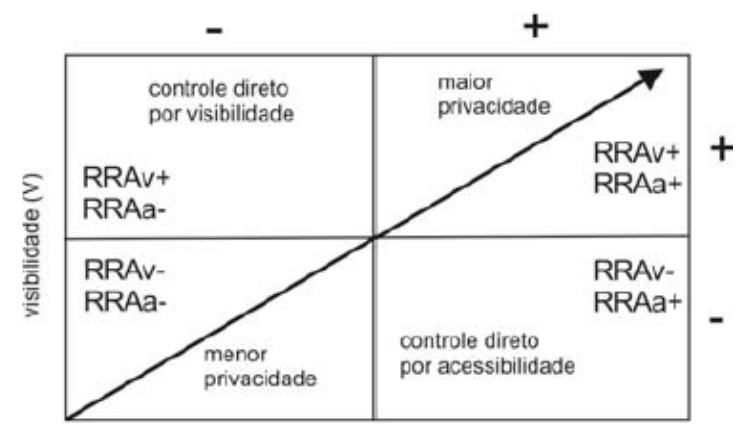

Fonte: Griz (2012, p. 175)

Figura 5 - Modelo ilustrativo de diagrama de quatro regiões para os valores de integraçãoo de um mesmo cômodo em vários exemplares

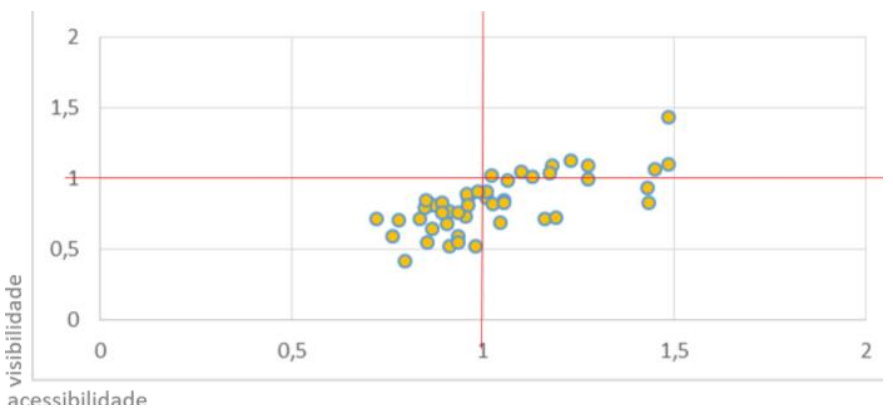

\section{Resultados e discussões}

Após identificar os padrões encontrados e ordenar os dados computados, percebe-se que há tanto permanências como alterações, no que diz respeito ao programa de necessidades e os aspectos dimensionais e configuracionais propostos na pesquisa. Mais do que simplesmente uma oferta ampliada do mercado imobiliário, os resultados indicam mudanças e manutenções nos modos de vida que são incididos de algum modo nos padrões ofertados pelas construtoras.

40 Carolino, A. da S.; Cunha, M. C.; Griz, C. 


\section{Programa de necessidades do apartamento}

No setor de serviço, os apartamentos até os anos 1990, em sua maioria, apresentam programas que contam com cozinha, área de serviço, dependência de empregada e banheiro de serviço, assim como encontrado nos apartamentos em Maceió, AL, por Lima e Toledo (2018). A partir dos anos 2000, na amostra estudada, esse setor passa a ser diminuído quanto ao seu programa de modo mais expressivo. Essa década apresenta, em sua maioria, apenas os ambientes indispensáveis a ele, que são "cozinha" e "serviço" - esse último muitas vezes diminuído à mínima área possível, por vezes apenas o espaço de um tanque. Fogem a essa regra os exemplares com áreas superiores aos $120 \mathrm{~m}^{2}$ e alguns exemplares com área próxima a $80 \mathrm{~m}^{2}$.

E, quando ofertadas, destacam-se as diferentes formas de tratar a dependência de empregada. Em alguns apartamentos esse cômodo passa a ser oferecido como um possível dormitório. Isso está presente tanto na conformação de quarto reversível como na nomenclatura e posição estratégica que aproxima mais esses ambientes da parte íntima do apartamento, permitindo ampliá-la (Figura 6). Tramontano, Pratschke e Marchetti (2000) ressaltam a comercialização do quarto reversível como uma tendência do desaparecimento do quarto de empregada, sendo oferecido como uma opção a mais de quarto para o setor íntimo.

No que se refere ao setor íntimo, o programa habitacional "básico" de uma suíte e dois quartos apresentados desde os anos 1980, sugerindo forte destinação à família nuclear, continua a ser ofertado. Mas, a partir dos anos 2000, surgem opções ainda mais diversificadas como apartamentos de apenas um quarto, sugerindo atender novos arranjos familiares, casais sem filhos, pessoas morando sós, viúvos, idosos, etc. Nas plantas dos apartamentos analisados com áreas superiores a $120 \mathrm{~m}^{2}$ os projetos apresentam de duas a quatro suítes (Figura 7), mostrando uma nova tendência nos modos de morar de uma faixa da sociedade que, a partir dos anos 2000, requer mais privacidade e isolamento para os ambientes íntimos.

No que diz respeito ao programa, o setor social se apresenta como o que teve menos alterações no decorrer dos anos, e no geral apresenta sala de estar, jantar e varanda. A partir dos anos 1990 alguns exemplares passam a oferecer mais ambientes neste setor (Figura 7), sugerindo que, a partir dessa década, é dada maior ênfase aos ambientes de receber, além de conferir status no momento de venda dos apartamentos de alto padrão (GRIZ, 2012). Griz (2012) aponta que esses ambientes "extras" oferecidos pelo mercado imobiliário funcionam também como estratégia de mercado a fim de garantir destaque a esses apartamentos.

Figura 6 - Residencial Saint Marie 1 e 2 originais e com proposta de reforma no quarto de serviço

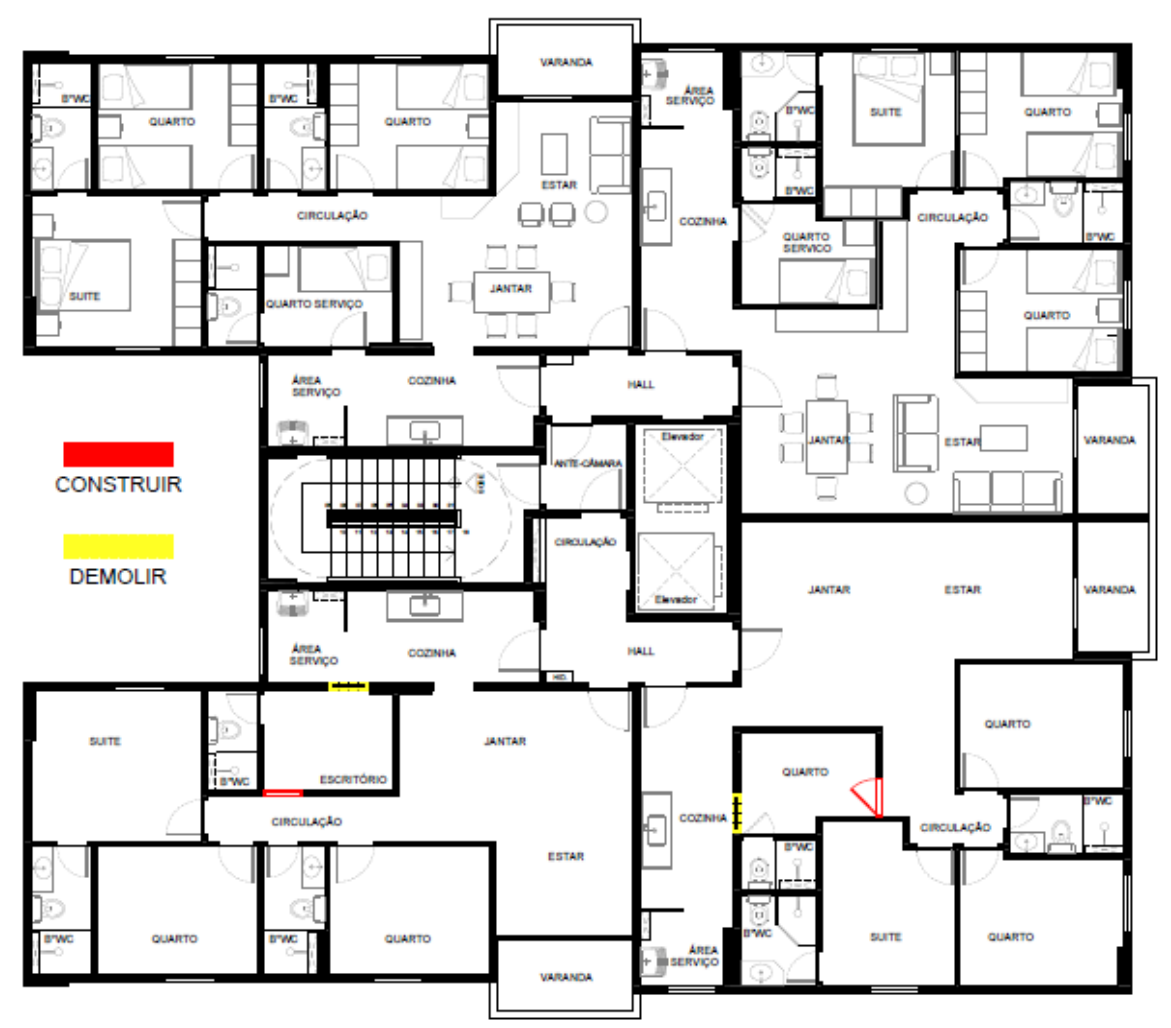

Fonte: adaptado do acervo do escritório Fábio Galiza Arquitetura. 
Figura 7 - Residencial Spazio di Ravenna tipo 2 com sala para 3 ambientes, um cômodo denominado "suíte/sala multiuso" e varanda com dois ambientes (2011)

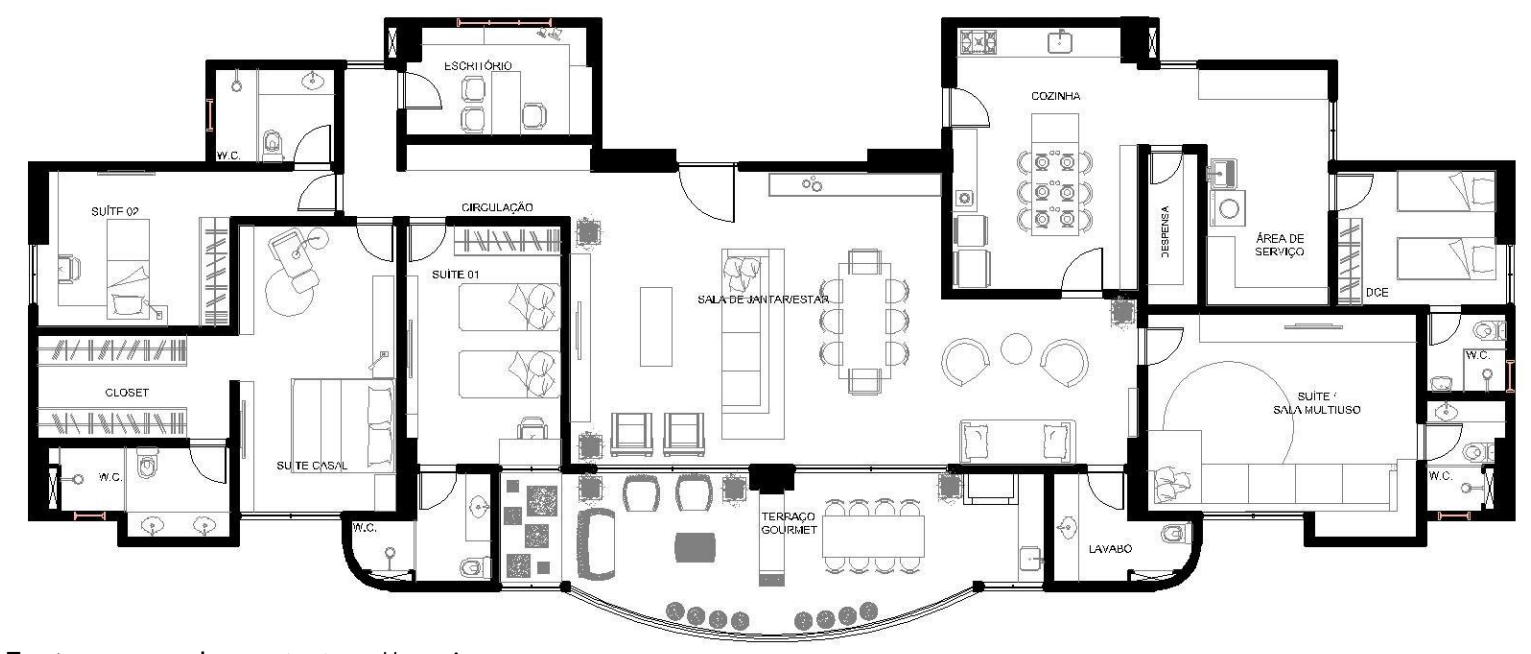

Fonte: acervo da construtora Massai.

Outro ponto relevante ao observar o setor social foi a presença marcante da varanda na amostra, o que sugere que esse cômodo ainda aparece como um espaço importante na comercialização dos empreendimentos. Trigueiro (2015) atribui que a presença desse ambiente também pode ser recorrente por heranças históricas, mais do que pelo seu uso frequente. França (2008) sugere que o oferecimento da varanda pode ocorrer como tática do mercado imobiliário para ganhar espaço a baixo custo, visto que os materiais de acabamento desse cômodo costumam ser mais baratos. Contudo, nos anos 2010, quando também é atribuída a função de receber visitas e preparar alimentos, esse ambiente passa a ter maior valorização com as chamadas varandas "gourmets", equipadas com bancadas e pia, e aparecem desde os maiores aos menores empreendimentos, como pode ser visto no exemplar Spazio Di Veneza 1 com $69 \mathrm{~m}^{2}$ (Figura 8).

\section{Análise da dimensão geométrica}

Quando observadas as questões dimensionais dos edifícios, inicialmente em relação à área total dos apartamentos, em sua maioria diminuíram cronologicamente. Os apartamentos com uma suíte e dois quartos, destinados à classe média, em 2010 se configuram em até $64 \mathrm{~m}^{2}$ e apresentam proporcionalmente o maior decréscimo da amostra. Os apartamentos de alto padrão decrescem menos sua área média, que em 1980 era de $130 \mathrm{~m}^{2}$ a $240 \mathrm{~m}^{2}$, e em 2010 aparece a partir de $100 \mathrm{~m}^{2}$, mas também em apartamentos com $245 \mathrm{~m}^{2}$.

Quando comparados à média da área do setor de cada década em relação à média da área total dos apartamentos, observou-se que existem variações para os projetos com diferentes programas de necessidades, conforme a quantidade de quartos. O que se pode notar é que os apartamentos com uma suíte e dois quartos apresentam proporções maiores na ocupação do apartamento ao setor íntimo, passando da média de $48 \%$ em 1980 para até $60 \%$ em alguns exemplares de 2010 (mesmo com a perda da varanda na suíte). Isso ocorre prioritariamente em detrimento do setor de serviço, mas por vezes do setor social (Figura 9).

Nesse grupo de apartamentos essa tendência é reforçada com a opção de retirada dos cômodos de dependência de empregada e banheiro de serviço a partir dos anos 2000, transferindo essa área para os ambientes mais privativos da família, confirmando a valorização desse setor. Assim como encontrado por França $(2008$, p. 237), na reforma de apartamentos em Brasília, "a tendência foi manter a área dos setores íntimo e social, diminuindo as áreas de serviço e circulação".

Nos apartamentos com mais de uma suíte o setor de serviço aumenta sua área proporcional, isso ocorre em função do aumento da área da cozinha. No entanto, apesar do aumento no número de suítes, a proporção do setor íntimo diminui em relação à área total do apartamento. Enquanto isso, o setor social nesses apartamentos aumenta sua área em relação à área total (Figura 10). Esses dados reforçam a proposta de nos empreendimentos de mais alto padrão haver uma valorização nos ambientes de receber visitas, garantindo assim o status requerido por esse grupo social (GRIZ, 2012). 
Figura 8 - Residencial Spazio di Veneza (2012)

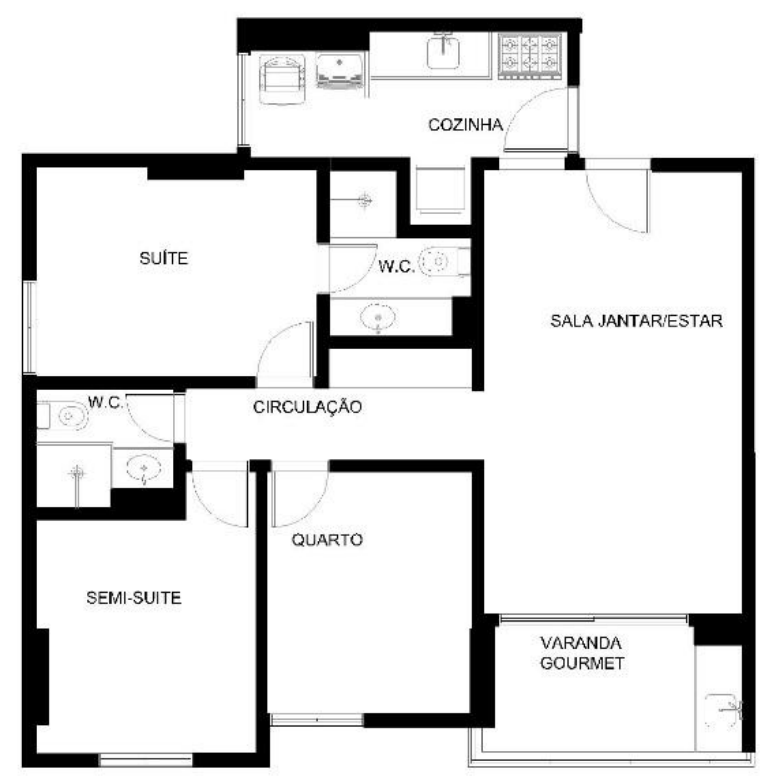

Fonte: acervo da construtora Massai.

Figura 9 - Média da área dos setores em relação à média da área total dos apartamentos com uma suíte e dois quartos

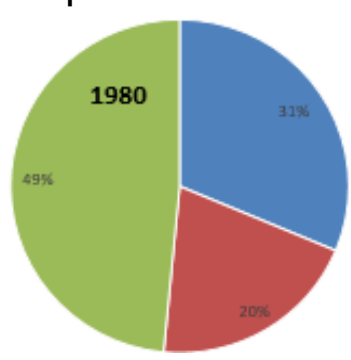

(a)

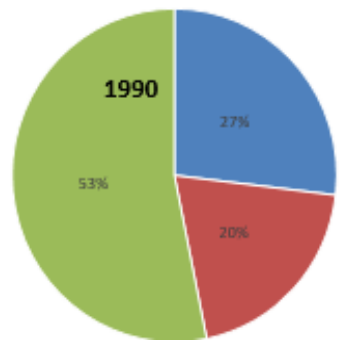

(b)

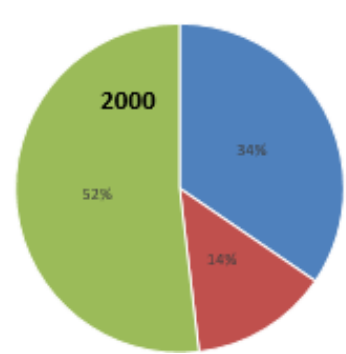

(c)

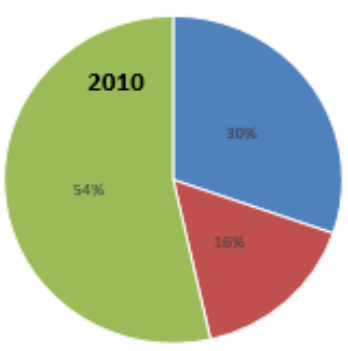

(d)

Nota: Legenda: " Social | Serviço = Intimo

Figura 10 - Média da área dos setores em relação à média da área total dos apartamentos com mais de uma suíte

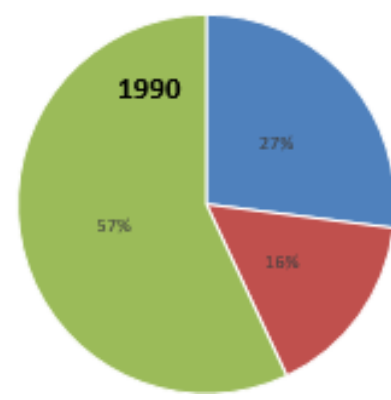

(a)

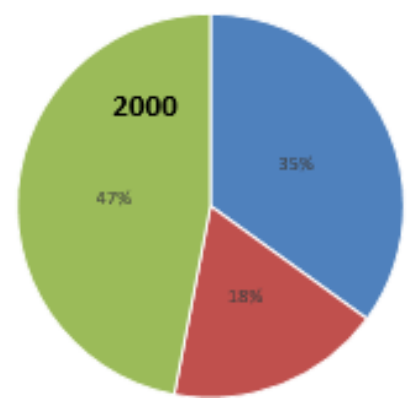

(b)

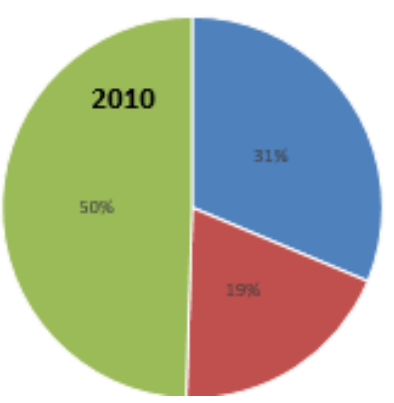

(c)

Nota: Legenda: = Social $\quad$ Serviço $=$ lintimo

Quando considerada a relação de proporção de um rótulo com a área total do apartamento, destacam-se os resultados encontrados para a suíte (Tabela 3). Nos programas de uma suíte e dois quartos, mesmo com a perda da varanda privativa a partir dos anos 2000, esse ambiente mantém sua média em relação à área total do apartamento, com $17 \%$, o que sugere o aumento proporcional de área do quarto e banheiro, reforçando um padrão de valorização pelos ambientes mais íntimos do apartamento. Enquanto nos projetos com mais de 
uma suíte, assim como o setor íntimo decresce por inteiro sua ocupação na planta do apartamento, a suíte reduz também a sua ocupação; isso se dá em consequência do crescimento - e consequente valorização - do setor social.

\section{Análise da configuração espacial}

Quanto à configuração espacial, inicialmente observa-se o padrão de acessibilidade dos setores. O tipo soc<serv<int está presente em todas as plantas dos anos 1980, nos anos 1990 permanece na maior parte das plantas com áreas superiores a $90 \mathrm{~m}^{2}$. Em 2000 está mais presente nas plantas de maior área total desse período, com mais de $200 \mathrm{~m}^{2}$, e nos anos 2010 essa relação entre os setores aparece em plantas com áreas variadas (Tabela 4).

Tendo em vista que a proposta do setor íntimo mais segregado que o serviço sugere um padrão com mais intimidade aos ambientes de convívio dos usuários do apartamento, a presença desse padrão mais forte nos anos 1980 e presente nos anos 2000/2010 nos apartamentos com áreas mais amplas sinaliza que há nesse grupo um perfil de famílias com maior poder aquisitivo e um perfil mais conservador com o passar dos anos nas relações do apartamento. A presença nessas últimas décadas em plantas com menores áreas (às vezes em apartamentos com um único quarto) ainda sugere que mesmo em arranjos familiares menores a valorização da privacidade nos espaços íntimos mantém-se requerida.

O padrão soc<serv=int aparece inicialmente na década de 1990 em apenas duas plantas. Nos anos 2000 e 2010 ela aparece de maneira mais expressiva. Esses dados sugerem uma aproximação do setor de serviço do íntimo mais forte nas décadas de 2000/2010 (Tabela 5).

Ao observar as modificações ocorridas nos grafos justificados perante as décadas de estudo, pode-se perceber que a partir dos anos 2000, em grande parte da amostra, em sua maioria nos apartamentos com áreas inferiores a $80 \mathrm{~m}^{2}$, a perda da conexão direta do exterior do apartamento para o setor de serviço (Figura 11).O acesso passa a ser dado prioritariamente pelo setor social, ou, às vezes, por uma pequena circulação que distribui social e serviço. Essa mudança para os acessos unificados aponta para a subversão em um padrão histórico de separação do acesso aos serviçais (FRANÇA, 2008).

As motivações para tais escolhas dos projetistas podem se dar por disponibilidade de área, número de apartamentos por pavimento ou ainda configuração da circulação comum do edifício. Mas, de fato, foram encontrados exemplares com configurações semelhantes (áreas próximas, mais de dois apartamentos por andar e possibilidade de separação dos acessos pela circulação comum) com tratamentos diferentes. Isso sugere ter sido uma opção do projeto apresentar uma ou duas entradas, conforme se pode observar nos exemplares dos edifícios Spazio Di Veneza com 69m² e Elisa Falcone com 64m² (Figuras 12 e 13 , respectivamente).

Os exemplares com áreas superiores aos $200 \mathrm{~m}^{2}$ mantêm os acessos separados e um setor de serviço mais segregado do íntimo, reproduzindo os padrões encontrados nas plantas dos anos 1980 (Figura 14). No entanto, ao observar a posição da cozinha, nos projetos mais recentes oferecidos pelo mercado imobiliário, nota-se que esta aparece mais integrada, assim como encontrado nos apartamentos analisados em Recife (GRIZ, 2012). Ora está mais próximo do setor social mostrando a intenção de ser um ambiente de receber, ora mais próximo do íntimo, aparentando ser de maior uso familiar (Figura 15).

Tabela 3 - Percentual de ocupação do setor íntimo e suíte

\begin{tabular}{c|c|c|c|c}
\hline \multirow{2}{*}{ Programa } & \multicolumn{2}{|c|}{ 1 suíte e 2 quartos } & \multicolumn{2}{c}{ Mais de uma suíte } \\
\cline { 2 - 5 } & \%setor & \%suíte & \% setor & \% suíte \\
\hline 1980 & 49 & 17 & - & - \\
1990 & 53 & 18 & 57 & 22 \\
2000 & 52 & 18 & 47 & 15 \\
2010 & 54 & 17 & 50 & 15 \\
\hline
\end{tabular}

44 Carolino, A. da S.; Cunha, M. C.; Griz, C. 
Tabela 4 - Número de vezes em que o primeiro padrão de setores encontrado aparece em relação à área total do apartamento para cada década

\begin{tabular}{c|c|c|c|c}
\hline soc $<$ serv $<$ int & Até 70 $\mathbf{~ m}^{\mathbf{2}}$ & $\mathbf{7 1 - 1 2 0} \mathbf{~ m}^{\mathbf{2}}$ & $<\mathbf{1 2 0} \mathbf{~ m}^{\mathbf{2}}$ & TOTAL \\
\hline 1980 & - & - & 8 & 8 \\
1990 & - & 6 & 1 & 7 \\
2000 & 3 & 3 & 6 & 12 \\
2010 & 5 & 10 & 7 & 22 \\
\hline
\end{tabular}

Tabela 5 - Número de vezes em que o segundo padrão de setores encontrado aparece em relação à área total do apartamento para cada década

\begin{tabular}{c|c|c|c|c}
\hline soc $<$ serv=int & Até 70 $\mathbf{~ m}^{\mathbf{2}}$ & $\mathbf{7 1 - 1 2 0} \mathbf{~ m}^{\mathbf{2}}$ & $<\mathbf{1 2 0} \mathbf{~ m}^{\mathbf{2}}$ & TOTAL \\
\hline 1980 & - & - & - & - \\
1990 & 2 & - & - & 2 \\
2000 & 18 & 5 & - & 23 \\
2010 & 8 & 10 & 1 & 19 \\
\hline
\end{tabular}

Figura 11 - Grafos justificados de acessibilidade Clarissa VI 2(1986), Poliedro III 2 (1992) e Atlantis Plaza 3(2009)

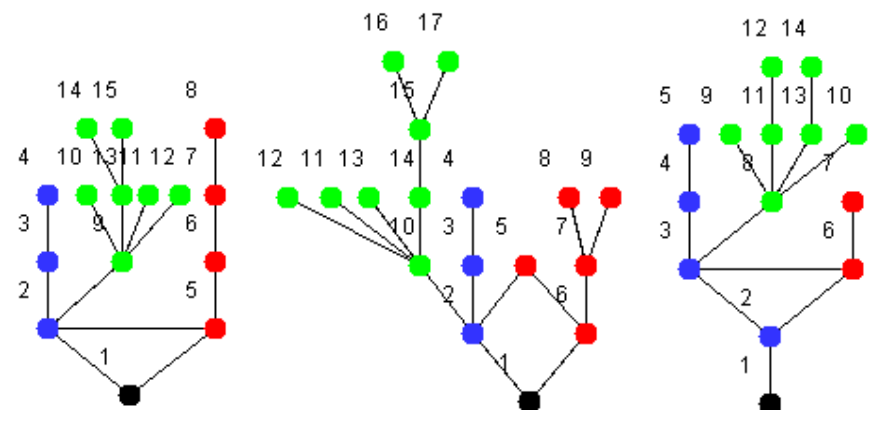

Figura 12 - Mapa convexo (a) e grafo justificado de acessibilidade (b) do Residencial Spazio Di Veneza (2012)

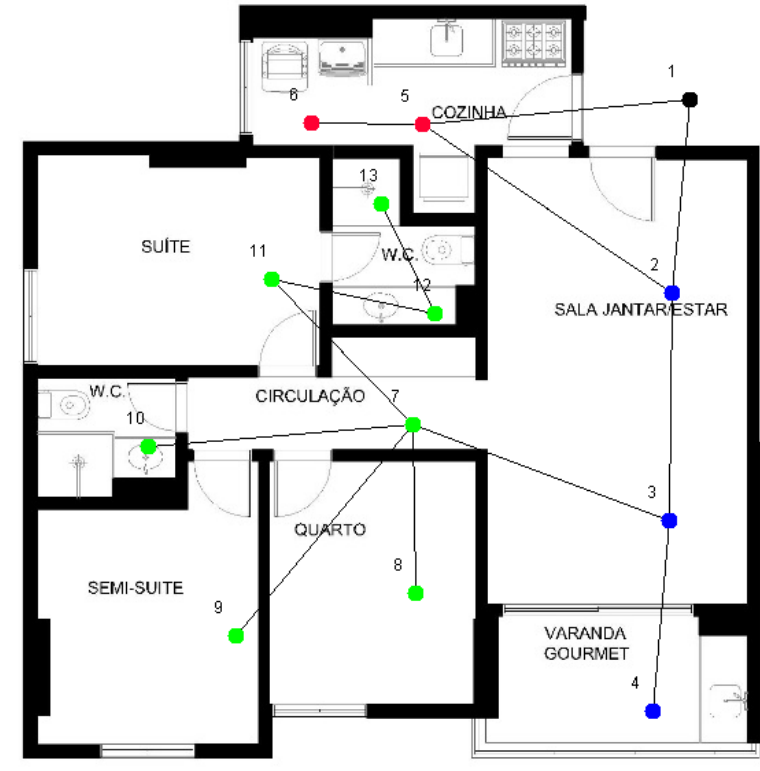

(a)
13

12

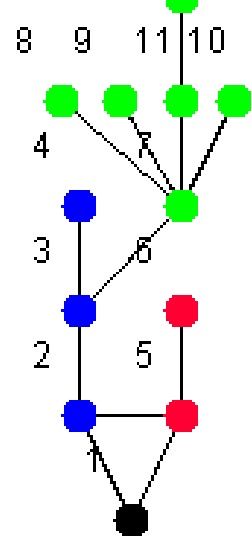

(b)

Fonte: adaptado do acervo da construtora Massai. 
Figura 13 - Mapas convexos (a) e grafo justificado de acessibilidade (b) do Residencial Elisa Falcone (2010)
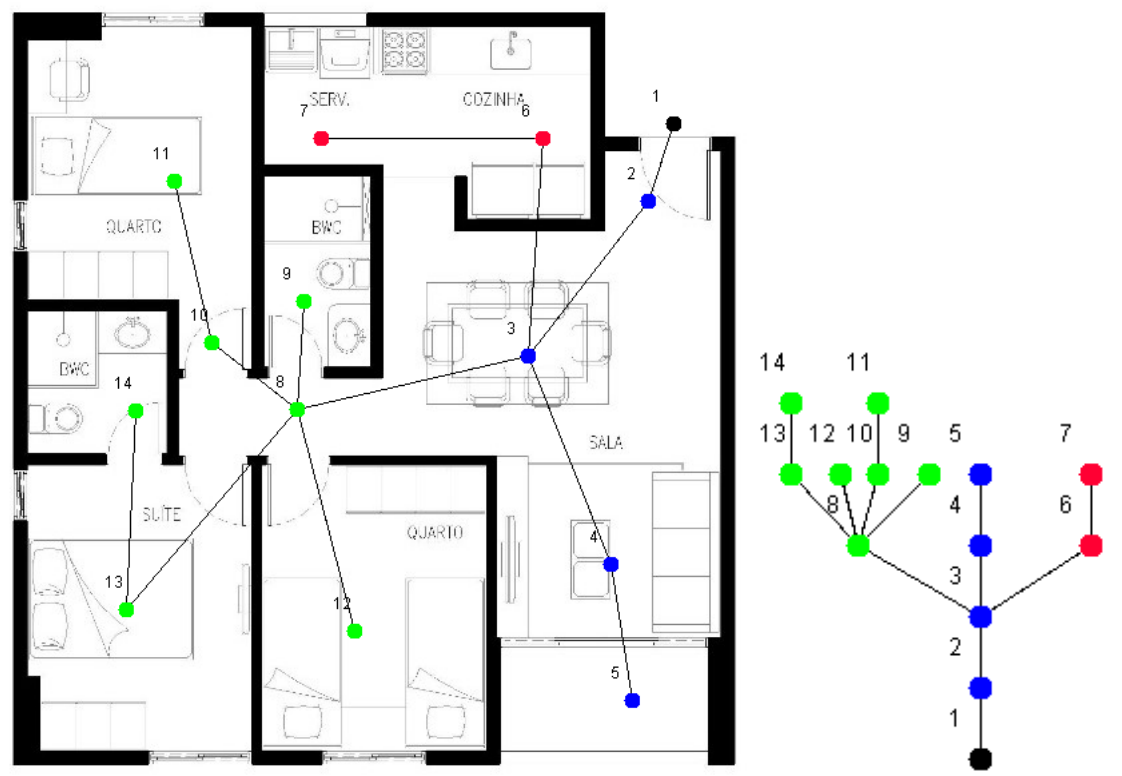

Fonte: adaptado do acervo do escritório Venâncio Toscano Arquitetura.

Figura 14 - Mapa convexo (a) e grafo justificado de acessibilidade (b) do Residencial Jamaica (1986), padrão da década de 1980

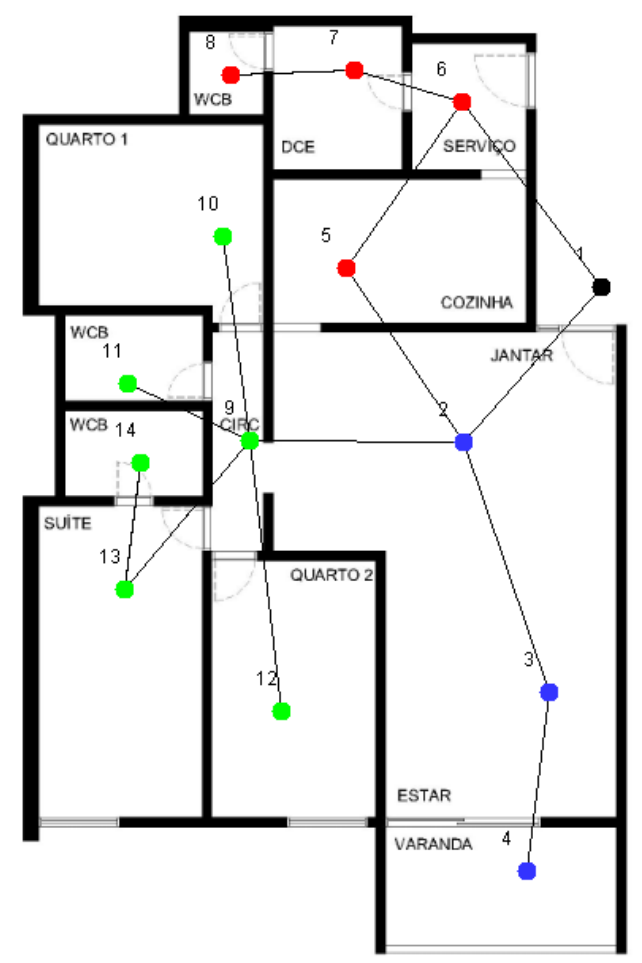

Fonte: adaptado de Diniz (2013). 
Figura 15 - Mapa convexo (a) e grafo justificado de acessibilidade (b)do Residencial Milton Cavalcanti (2002), um dos modelos encontrados no anos 2000

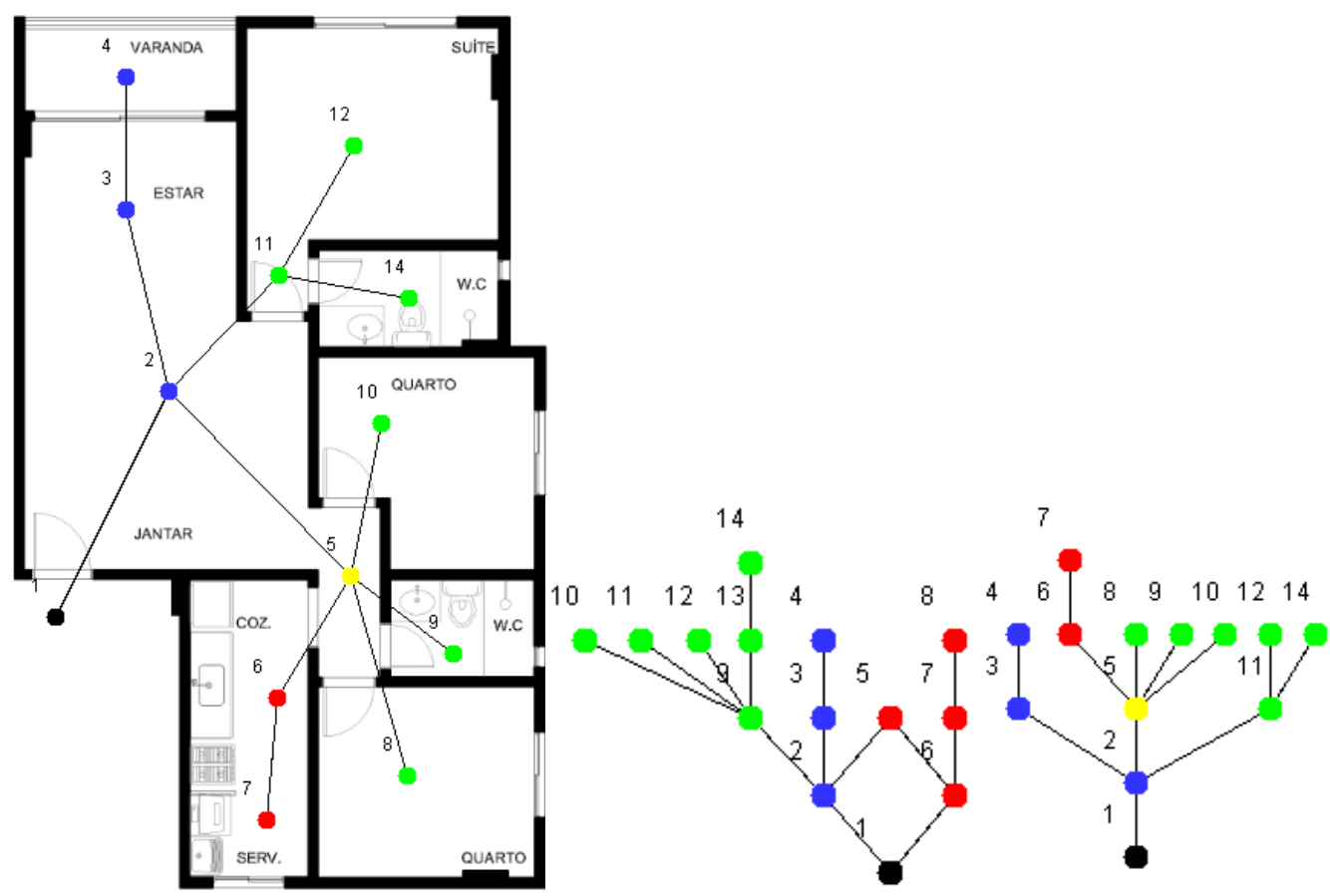

Fonte: adaptado do acervo do escritório Paulo Macedo Arquitetura.

Ao observar os modelos de quatro regiões se destacam os resultados encontrados para a suíte. O aumento da segregação por visibilidade (quadrante superior direito), com poucos exemplares apresentando integração por acessibilidade (quadrante inferior direito), reforça a tendência por mais intimidade nesses espaços e a aparente busca por mais privacidade nos novos apartamentos (Figura 16).

De modo que é possível identificar variações na oferta por diferentes áreas e programas que parecem tentar acompanhar as novas demandas de diferentes grupos familiares. No entanto, o que fica visível é que a maneira de organizar o espaço doméstico está, em certa medida, sendo adotada pelo mercado imobiliário de forma diretamente proporcional à área dos apartamentos. As plantas com menores áreas aproximam setores íntimo e serviço, subvertendo os padrões dos anos 1980. De maneira contrária, as com mais espaços segregam as áreas privativas da habitação. Essa forma rígida de apresentar o espaço doméstico aparenta ignorar os diversos modos de morar de diferentes composições familiares.

\section{Conclusão}

A pesquisa que deu suporte a este artigo buscou analisar as plantas de apartamento na cidade de João Pessoa, nas décadas e recorte espacial estudados, visando à identificação de reproduções e renovações nos arranjos espaciais. É importante enfatizar que os resultados encontrados referem-se a um eixo da cidade com características que podem lhe ser particulares ou se assemelharem a outras localidades que não foram exploradas nesta pesquisa.

Este artigo buscou contribuir com resultados que fomentem o debate sobre a atual produção imobiliária e a possível adequação à realidade social dos tempos atuais. O estudo revelou que a produção dos projetos de apartamento - considerando a amostragem - conserva apenas parte das relações entre seus espaços. Há permanências históricas no espaço de morar, como o papel de grande espaço intermediador dado à sala de jantar e à distribuição funcional em setores. Em contrapartida, há perdas de atributos considerados consagrados da moradia, como a separação dos acessos e dos espaços íntimos e de serviço, desmitificando a hierarquia espacial doméstica.Esses e outros achados fortalecem as mudanças apontadas nos estudos sociais como a crescente ausência da funcionária doméstica que vem sendo substituída pela diarista, a diminuição no tamanho dos grupos familiares, bem como a maior valorização da intimidade e privacidade de cada membro da família. 
Figura 16 - Modelos de quatro regiões para suíte

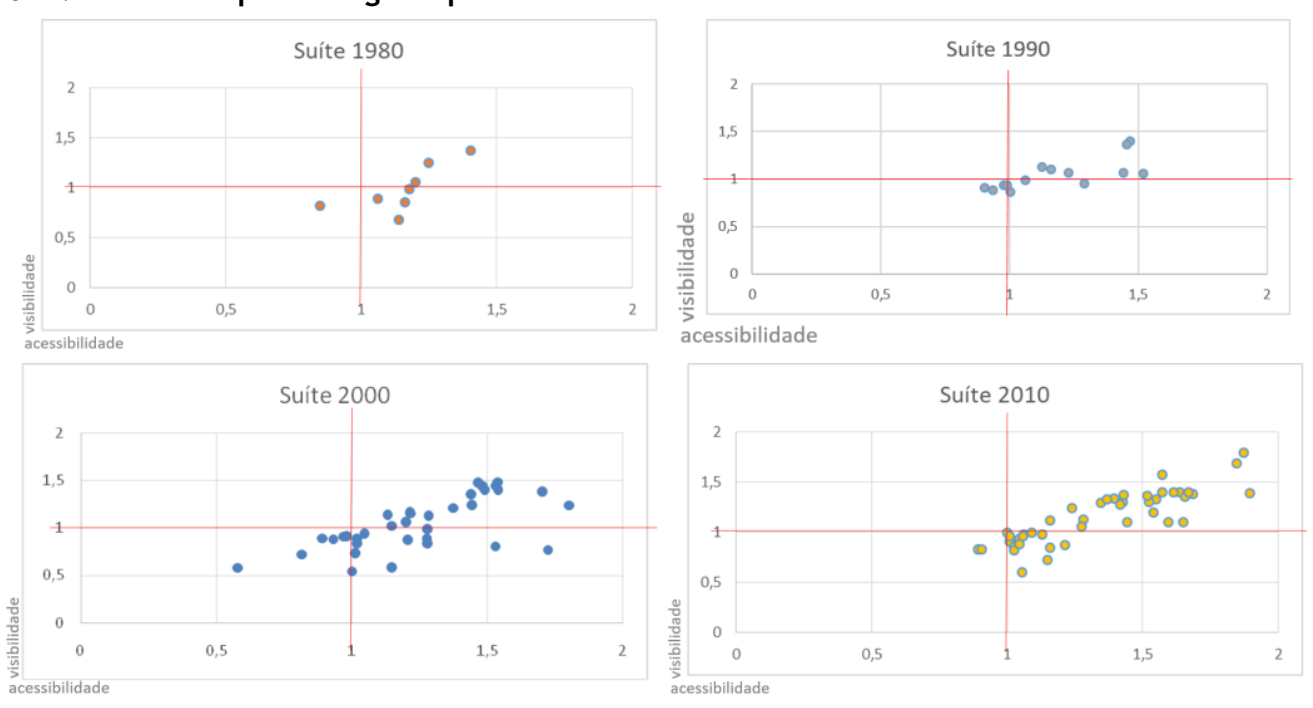

A característica marcante encontrada é a diferenciação dos atributos do espaço para plantas com diferentes áreas, de modo que as mudanças no tamanho dos arranjos familiares não estão diretamente relacionadas ao tamanho dos espaços, mas, sim, às exigências que cada família tem para os padrões espaciais e de como esses devem atender às expectativas dos modos de vida para cada grupo familiar. Espaços mais individualizados que proporcionam maior privacidade ocorrem em apenas parte dos projetos ofertados pelo mercado imobiliário, aqueles com maiores áreas, enquanto a demanda por espaços mais integrados para atender uma nova forma de morar são apresentados apenas nos apartamentos de menor área.

Os espaços oferecidos pelo mercado apresentam características que visam o apartamento apenas como um produto a ser comercializado. De fato, o apartamento é também hoje visto como um produto de consumo, por vezes até de investimento por parte da população, porém não deve ser visto apenas por essa ótica. Aponta-se para a necessidade de melhoria na qualidade dos projetos e estratégias públicas e de mercado que atendam tanto a qualidade dos espaços de morar como os diversos atores envolvidos nesse modelo de negócio.

\section{Referências}

AMORIM, L. The sector's paradigm: understanding modern funcionalism in domestic space. In:

INTERNATIONAL SPACE SYNTAX SYMPOSIUM, 1., London, 1997, Londres. Proceedings [...] London: University College of London, 1997.

AMORIM, L.; LOUREIRO, C. Diz-me teu nome, tua altura e onde moras e te direi quem és: estratégias de marketing e a criação da casa ideal - parte 1. 2005. Disponível em:

http://www.vitruvius.com.br/revistas/read/arquitextos/05.057/505.Acesso em: 23 out. 2017.

AUGÉ, M. Não-lugares: introdução a uma antropologia da supermodernidade. São Paulo, Campinas: Papirus, 1992.

CHAVES, C. Verticalização em João Pessoa: novo ciclo da modernização (1950-1970). João Pessoa, 2014. In: COTRIM, M; TINEN, N. (org.). Urdidura da modernidade: Arquitetura Moderna na Paraíba I. João Pessoa: Editora Universitária PPGAU/UFPB, 2014.

DAMATTA, R. A casa e a rua: espaço, cidadania, mulher e morte no Brasil. Rio de Janeiro: Guanabarra Koogan, 1991.

DINIZ, Y. A forma do edifício alto: análise de edifícios residenciais em João Pessoa-PB (1979-1990). João Pessoa, 2013.

FARIA, G.; COUTINHO, C.; MACEDO, L. Proletárias do lar: o atual cenário do trabalho doméstico em Minas Gerais. Minas Gerais, 2013. Disponível em: http://livrozilla.com/doc/1653909/prolet\%C3\%A1riasdo-lar--o-atual-cen\%C3\%A1rio-do. Acesso em: 5 dez. 2019. 
FRANÇA, F. Indisciplina que muda a arquitetura: a dinâmica do espaço doméstico no Distrito Federal. Brasília, 2008. Tese (Doutorado em Arquitetura e Urbanismo) - Universidade de Brasília, Brasília, 2008.

GOLDANI, A. A. As famílias no Brasil contemporâneo e o mito da desestruturação. Cadernos Pagu, Campinas, v. 1, p. 67-110, 1993.

GRIZ, C. Quando o luxo é necessário: sobre projetos de apartamento no Recife. Pernambuco, 2012.Tese (Doutorado em Desenvolvimento Urbano) - Universidade Federal de Pernambuco, Pernambuco, 2012.

HANSON, J. Decoding homes and houses. Cambridge: Cambridge University Press, 1998.

HILLIER, B.; HANSON, J. The social logic of space. Cambridge: Cambridge University Press, 1984.

KENT, S. A cross-cultural study of segmentation, architecture and use of space. In: KENT, S. (ed.). Domestic architecture and the use of space: an interdisciplinary cross-cultural study. Cambridge: Cambridge University Press, 1997.

LIMA, J. C. R.; TOLEDO, A. M. A permanência do dormitório da empregada nos apartamentos: estudo comparativo nas décadas de 1960 a 1990 em Maceió/AL. Gestão e Tecnologia de Projetos, São Carlos, v. 13, n. 3, p. 79-96, dez. 2018.

MELO, H. O serviço doméstico remunerado no Brasil: de criadas a trabalhadoras. Texto para Discussão IPEA N ${ }^{\circ}$ 565. Rio de Janeiro, junho de 1998.

MONTEIRO, C. Activity analysis in houses of Recife. In: INTERNATIONAL SPACE SYNTAX SYMPOSIUM, 1., London, 1997, Londres. Proceedings [...] Londres: University College of London, 1997.

MOTTA, A. Emprego doméstico: revendo o novo. Caderno CRH, v. 16, p. 31-49, jan./jun. 1992.

PAULA, V. D. C. Espaço e sociedade: apartamentos no Rio de Janeiro no século XX. Rio de Janeiro, 2007. 419 f. Tese (Doutorado em Arquitetura e Urbanismo) - Universidade Federal do Rio de Janeiro, Rio de Janeiro, 2007.

PETRINI, G.; ALCANTARA, M. A. R.; MOREIRA, L. V. C. Família na contemporaneidade: uma análise conceitual. In: MENEZES, J. E.; CASTRO, M. G. (ed.). Família, população, sexo e poder: entre saberes e polêmicas. São Paulo: Paulinas, 2009.

PREFEITURA MUNICIPAL DE JOÃO PESSOA. [Mapas de geoprocessamento]. Disponível em: http://geo.joaopessoa.pb.gov.br/digeoc/htmls/cad.html. Acesso em: 1 set. 2017.

SANT'ANNA, M. J. G. Dinâmica socioespacial, habitação e família na metrópole do Rio de Janeiro. Cadernos Metrópole, 1998.

TRAMONTANO, M. Novos modos de vida, novos espaços de morar. São Carlos, 1993.

TRAMONTANO, M. Habitações, metrópoles e modos de vida. Por uma reflexão sobre o espaço doméstico contemporâneo. 3o. Prêmio Jovens Arquitetos, categoria "Ensaio Crítico". São Paulo: Instituto dos Arquitetos do Brasil / Museu da Casa Brasileira, 1997. 210mm x 297mm. 10 p. Ilustr. Disponível em: http://www.nomads.usp.br/site/livraria/livraria.htmlAcesso em: 18 set. 2016.

TRAMONTANO, M. Apartamentos e vida privada na cidade de São Paulo. São Carlos, 2004. Tese (Livre Docência) - Universidade de São Paulo, São Carlos, 2004.

TRAMONTANO, M.; PRATSCHKE, A.; MARCHETTI, M. Um toque de imaterialidade: o impacto das novas mídias no projeto do espaço doméstico. In: SEMINÁRIO INTERNACIONAL PSICOLOGIA E PROJETO DO AMBIENTE CONSTRUTIVO, Rio de Janeiro, 2000. Anais [...] Rio de Janeiro, 2000.

TRAMONTANO, M. Interactive living-spaces: 12 Preliminary Notes. In: NIETO, I.; VEGA, R.; TELLO, I. (org.). Installing: art and technology / Instalando: arte y tecnologia. Santiago: Troyano, 2007.

TRIGUEIRO, E. The dinner procession goes to the kitchen. In: INTERNATIONAL SPACE SYNTAX SYMPOSIUM, 1., London, 1997. Proceedings [...] London: University College of London, 1997.

TRIGUEIRO, E. Is there a Brazilian home? An overview of domestic space and modes of life. In: INTERNATIONAL SPACE SYNTAX SYMPOSIUM, 10., London, 2015. Proceedings [...] London: Space Syntax Laboratory, The Bartlett School of Architecture, University College London, 2015.

VILLA, S. Os formatos familiares contemporâneos: transformações demográficas. OBSERVATORIUM: Revista Eletrônica de Geografia, v.4, n. 12, p. 2-26, dez. 2012. 
Aline da Silva Carolino

Departamento de Arquitetura e Urbanismo | Universidade Federal da Paraíba | Av. Cônego Luiz Gonzaga de Oliveria, 34 | João Pessoa PB - Brasil | CEP 58030-212 | Tel.: (83) 99906-7020 | E-mail: alinecarolino@gmail.com

\section{Marcio Cotrim Cunha}

Faculdade de Arquitetura | Universidade Federal da Bahia | Rua Caetano Moura, 121, Federação | Salvador - BA - Brasil | CEP 40210-905 | CEP (71) 3283-5883 | E-mail: marciocotrim@gmail.com

\section{Cristiana Griz}

Departamento de Expressão Gráfica | Universidade Federal de Pernambuco | Av. dos Reitores, s/n | Recife - PE - Brasil | CEP 50670-901 | Tel.: (81) 98808-4422 | E-mail: cristiana.sgriz@ufpe.br

\section{Ambiente Construído}

Revista da Associação Nacional de Tecnologia do Ambiente Construído

Av. Osvaldo Aranha, $99-3^{\circ}$ andar, Centro

Porto Alegre - RS - Brasil

CEP $90035-190$

Telefone: +55 (51) 3308-4084

Fax: +55 (51) 3308-4054

www.seer.ufrgs.br/ambienteconstruido

E-mail: ambienteconstruido@ufrgs.br

50 Carolino, A. da S.; Cunha, M. C.; Griz, C. 